\title{
Le syndrome de Perthes ou asphyxie traumatique
}

\section{Perthe's syndrome or traumatic asphyxia}

\author{
E. Mazocky • B. Vallé • M. Biais
}

Reçu le 18 octobre 2012 ; accepté le 13 décembre 2012

(C) SFMU et Springer-Verlag France 2013
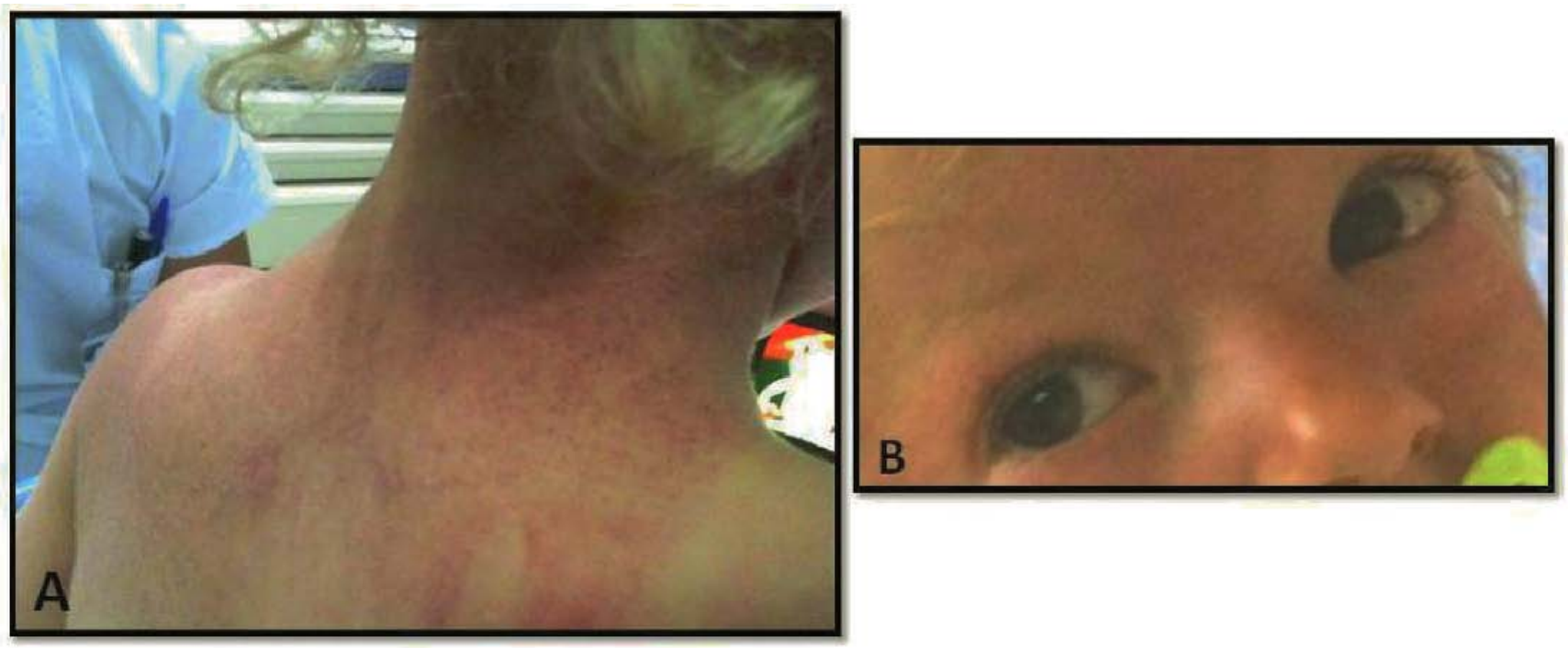

Fig. 1 A. Pétéchies du territoire cave supérieur

B. Pétéchies du territoire cave supérieur et pétéchies conjonctivales

Une fillette de 19 mois s'est retrouvée coincée sous les roues d'une voiture qui faisait marche arrière. À son arrivée dans le service des urgences trente minutes après l'accident, elle présentait un syndrome de Perthes, ou asphyxie traumatique, décrit en 1900 par Georg Perthes [1], qui est l'expression

E. Mazocky $\cdot$ B. Vallé $(\bowtie) \cdot$ M. Biais

Pôle des urgences adultes, SAMU/SMUR,

CHU de Bordeaux, hôpital Pellegrin,

place Amélie Raba-Léon, F-33000 Bordeaux, France

e-mail : baptiste.valle@chu-bordeaux.fr

\section{Biais}

Université Bordeaux Segalen, rue Léo Saignat, F-33000 Bordeaux, France clinique d'une compression thoracique courte et brutale entraînant une hyperpression veineuse cave supérieure. Il en résulte une triade cutanée : pétéchies du territoire cave supérieur (Fig. 1), hémorragies sous-conjonctivales (Fig. 1B) et cyanose cervicofaciale. Le traitement est aspécifique et symptomatique. Chez l'enfant, ce syndrome est plus fréquemment favorable du fait d'une plus grande élasticité thoracique [2].

\section{Références}

1. Perthes G (1900) À propos de la stase par compression. Dtsch Z Chirurg 55:384-92

2. El Koraichi A, Benafitou R, Tadili J, et al (2012) Traumatic asphyxia or Perthe's syndrome. About two paediatric cases. Ann Fr Anesth Reanim 31:259-61 